\title{
Crystalline Nature of Metal Spikes and Silicon Inclusions in Ag/Al Screen-Printing Metallization
}

\author{
Susanne Fritz, Stefanie Riegel, Adnan Hammud, Hakan Deniz, and Giso Hahn, Member, IEEE
}

\begin{abstract}
For contacting boron emitters by screen-printing metal pastes, up to now, it has been necessary to add a small amount of Al to the Ag paste to facilitate a reasonable contact resistivity. With the addition of $\mathrm{Al}$ to the $\mathrm{Ag}$ paste, deep $\mathrm{Ag} / \mathrm{Al}$ spikes appear, which can be deep enough to penetrate the emitter and, therefore, affect the emitter and space charge region, and, finally, affect the performance of the solar cell. In this paper, a transmission electron microscopy (TEM) analysis of these Ag/Al spikes is presented. The crystalline nature of the $\mathrm{Ag} / \mathrm{Al}$ spikes is revealed for different surface structures of the crystalline $\mathrm{Si}$ wafer and different Al contents in the screen-printing paste. This result is confirmed by X-ray diffraction measurements of etched-back contacts. Additionally, TEM energy-dispersive $\mathrm{X}$-ray spectroscopy facilitates the examination of the Si-rich inclusions found in the $\mathrm{Ag} / \mathrm{Al}$ spikes. They prove to be multicrystalline Si precipitates with at least 99 at $\% \mathrm{Si}$. The observations help to understand the contact formation process of Al containing Ag screen-printing pastes and support the previously presented model.
\end{abstract}

Index Terms-Ag/Al, boron emitter, crystallinity, screenprinting, transmission electron microscopy (TEM), X-ray diffraction (XRD).

\section{INTRODUCTION}

$\mathbf{S}$ CREEN-PRINTING is a commonly used metallization technique for contacting solar cells. For the front-side metallization of crystalline p-type $\mathrm{Si}$ solar cells, $\mathrm{Ag}$ screen-printing pastes are frequently used. The contact formation process of these $\mathrm{Ag}$ pastes was thoroughly investigated [1]-[3]. For Ag screen-printing pastes on $\mathrm{n}^{+}$-emitters, small Ag spikes can be found at the $\mathrm{Si}$ surface. The crystalline nature of these Ag spikes was exposed by Ballif et al. [4]. It is generally assumed that these $\mathrm{Ag}$ crystals are an indispensible condition for a low specific contact resistance [4]-[6]. For contacting $\mathrm{p}^{+}$boron emitters, $\mathrm{Ag}$ screen-printing pastes containing a small amount of $\mathrm{Al}$ are commonly used to reach low enough contact resistivities [7]-[9]. However, latest results show that in special cases, pure $\mathrm{Ag}$ paste might give a good contact as well [10]. The contact formation process of $\mathrm{Ag} / \mathrm{Al}$ pastes differs from that of pure $\mathrm{Ag}$ screen-

S. Fritz, S. Riegel, A. Hammud, and G. Hahn are with the Department of Physics, University of Konstanz, Konstanz 78464, Germany (e-mail: susanne.fritz@uni-konstanz.de; stefanie.riegel@uni-konstanz.de; hammud@ gmx.de; giso.hahn@uni-konstanz.de).

H. Deniz is with the Max Planck Institute of Microstructure Physics, Halle 06120, Germany (e-mail: hdeniz@mpi-halle.mpg.de). printing pastes [11]. The contacts feature deeper metal spikes that can be deep enough to penetrate the emitter. The influence of these spikes on cell performance was investigated by different groups [12]-[14] and is a topic of ongoing research activities. The investigation of the contact formation process and the mechanism behind the growth of these metals spikes can lead to a further understanding of their impact on cell performance and possibly help to develop pastes that avoid this negative impact.

However, up to now, most studies dealing with the microstructure of screen-printed $\mathrm{Ag} / \mathrm{Al}$ contacts were based on scanning electron microscopy (SEM) analysis and, therefore, lack of information about the crystallographic structure and orientation of the $\mathrm{Ag} / \mathrm{Al}$ contact spots [11], [15], [16]. In addition, the spatial resolution of SEM energy-dispersive X-ray (EDX) spectroscopy is limited to $>1 \mu \mathrm{m}$ as a result of the large activation volume of the electrons in a bulk sample. As the transmission electron microscopy (TEM) lamellas prepared in this study have a thickness of $<100 \mathrm{~nm}$ and the acceleration voltage is higher than in SEM systems [17], the spatial resolution of TEM EDX is much better, and smaller areas can be investigated as well.

In this paper, a detailed TEM analysis of metal spikes occurring below screen-printed $\mathrm{Ag} / \mathrm{Al}$ contacts is presented. The nature of the $\mathrm{Ag} / \mathrm{Al}$ spikes is investigated for $\mathrm{Si}$ samples with different surface structure and $\mathrm{Ag} / \mathrm{Al}$ pastes with different $\mathrm{Al}$ content. The TEM investigation of the metal spikes is supported by X-ray diffraction (XRD) measurements of etched-back contacts. Additionally, Si inclusions found in the metal spikes are analyzed by means of TEM. The results are discussed with regard to the model for contact formation of $\mathrm{Ag} / \mathrm{Al}$ pastes to boron emitters presented in [11]. According to that model, contact formation is based on melting of $\mathrm{Al}$ particles, which dissolve the surrounding $\mathrm{Ag}$ forming an $\mathrm{Ag} / \mathrm{Al}$ phase at temperatures above $660{ }^{\circ} \mathrm{C}$. Where the $\mathrm{Ag} / \mathrm{Al}$ gets in contact with the Si surface, $\mathrm{Si}$ is dissolved. During cool down of the wafers, $\mathrm{Ag} / \mathrm{Al}$ spikes solidify in these regions and Si precipitates in the $\mathrm{Ag} / \mathrm{Al}$ phase. The role of the glass frit in the paste is primarily to remove the antireflection layer.

\section{SAMPLE PREPARATION AND EXPERIMENTAL DETAILS}

For the analysis, (100)-oriented $\mathrm{n}$-type $\mathrm{Cz} \mathrm{Si}$ wafers were used. The wafers were treated in different ways to realize different surface structures: Wafers were either etched in $\mathrm{NaOH}$ to realize plane (100)-oriented surfaces or alkaline textured to obtain a pyramidal surface texture with (111)-oriented pyramid planes or plasma textured [16]. After cleaning, a $50-\Omega / \square$ emitter was diffused in a $\mathrm{BBr}_{3}$-based open tube furnace process. The removal of the borosilicate glass was 
followed by the deposition of a 75-nm-thick plasma-enhanced chemical vapor deposition (PECVD) $\mathrm{SiN}_{\mathrm{x}}: \mathrm{H}$. To investigate the influence of the $\mathrm{SiN}_{\mathrm{x}}: \mathrm{H}$ layer, a group of samples with alkaline surface texture but without $\mathrm{SiN}_{\mathrm{x}}: \mathrm{H}$ was prepared as well. In the following, an Al-containing Ag paste with a medium Al content was screen-printed on the wafers. For the alkaline textured wafers with $\mathrm{SiN}_{\mathrm{x}}: \mathrm{H}$, an $\mathrm{Ag}$ paste with a medium $\mathrm{Al}$ content and a paste with a high $\mathrm{Al}$ content, but apart from that the same composition, were screen-printed. Then, the samples were fired in a belt furnace with a peak firing temperature of $\approx 810{ }^{\circ} \mathrm{C}$ measured on the wafer. For preparation of TEM lamellas, the samples were first etched in hydrofluoric acid (HF 5\%), removing the glass layer of the contact fingers and the bulk metal. The remaining Ag/Al contact spots were analyzed by means of SEM. Then, adequate contact spots were selected and TEM lamellas were prepared by focused ion beam (FIB). After cutting the lamellas out of the samples, they were positioned on a TEM grid and thinned to $<100 \mathrm{~nm}$. The TEM analysis was then conducted at a JEOL JEM-2200FS high-resolution TEM (HRTEM) (200 kV) and an FEI TITAN 80-300 probe-corrected scanning/transmission electron microscopy (300 kV).

For the XRD measurement, alkaline textured wafers with $\mathrm{SiN}_{\mathrm{X}}: \mathrm{H}$ layer were selected and processed in the same way as the TEM samples. To guarantee a high amount of Ag/Al spikes at the $\mathrm{Si}$ surface, the $\mathrm{Ag} / \mathrm{Al}$ paste with high amount of $\mathrm{Al}$ was screen-printed. The samples were etched back in HF as well to remove the contact finger and allow the examination of the $\mathrm{Ag} / \mathrm{Al}$ contact spots. The XRD measurements were conducted under a fixed grazing incidence angle of $2^{\circ}$ to minimize the signal of the Si substrate.

\section{RESULTS}

\section{A. Wafer With SiN $_{\mathrm{x}}:$ H Layer}

Fig. 1(c) and (d) shows scanning transmission electron microscopy (STEM) images of an Ag/Al spike grown into the $\mathrm{Si}$ surface of an alkaline textured wafer with $\mathrm{SiN}_{\mathrm{x}}: \mathrm{H}$ layer. Dark lines are visible in the metal. The Si diffraction pattern (a) shows the $\langle 011\rangle$ orientation of the Si crystal. In Fig. 1(b), the selected area diffraction pattern (SAED) of the $\mathrm{Ag} / \mathrm{Al}$ spike recorded under the same sample tilt can be seen. The crystalline nature of the metal is clearly visible, but there is no particular orientation relation between the Si lattice and the metal for this sample tilt. The SAED does not change when moving through the Ag/Al spike and over the dark lines in the STEM images. Fast Fourier transformation (FFTs) performed at HRTEM images of the same sample show as well the same point diffraction pattern at different areas in the metal spike. Therefore, we conclude that the $\mathrm{Ag} / \mathrm{Al}$ spike is monocrystalline.

The composition of the metal spikes of the different samples was investigated by TEM EDX. The crystals consist of Ag with a low-Al content measured between 1.5 and 5 at $\%$ and up to 3 at $\%$ Si [compare Fig. 6(b)]. For the investigated samples, the $\mathrm{Al}$ fraction is independent of the $\mathrm{Al}$ content of the paste. The latter can be explained by the $\mathrm{Al}$ distribution in the paste. The $\mathrm{Al}$ is not homogeneously distributed in the $\mathrm{Ag}$ paste. Al particles with a size of some micrometers are randomly located in the
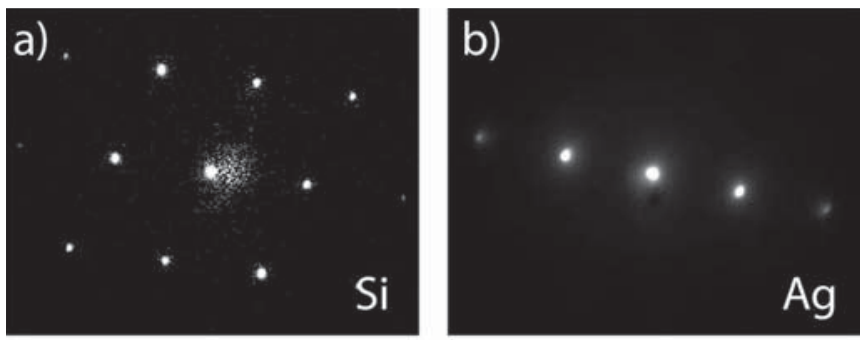

c)
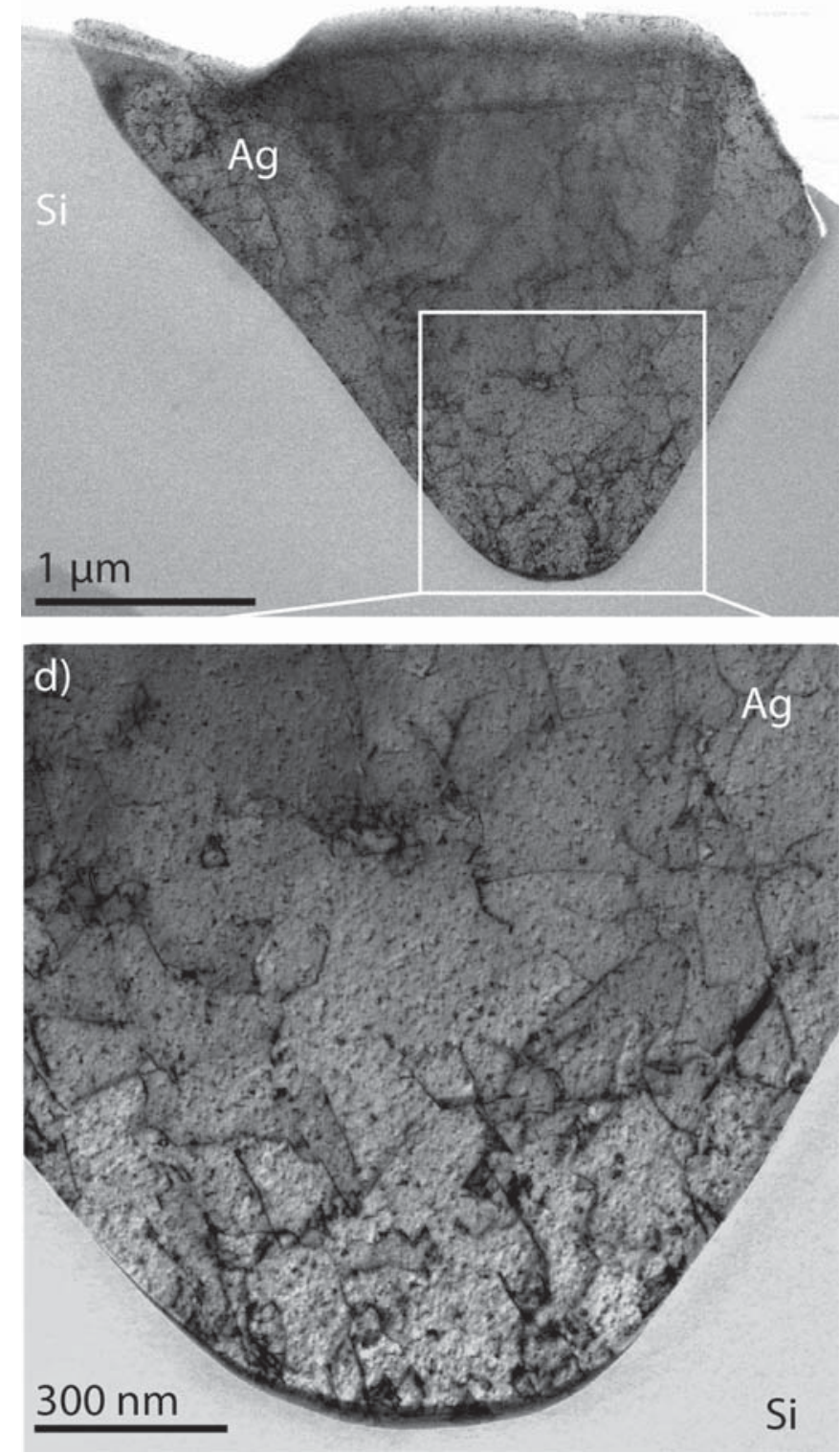

Fig. 1. (a), (b) Diffraction patterns and (c), (d) STEM images of Si surface with grown in $\mathrm{Ag} / \mathrm{Al}$ spike.

paste. As explained in [11], these particles melt and dissolve the surrounding Ag. Where this $\mathrm{Ag} / \mathrm{Al}$ phase gets in contact with the $\mathrm{Si}$ surface, $\mathrm{Ag} / \mathrm{Al}$ spikes can be found after cooling down the wafers. When the screen-printing paste contains a higher $\mathrm{Al}$ fraction, that means more $\mathrm{Al}$ particles, these events occur more frequently. However, the Al content of a single $\mathrm{Ag} / \mathrm{Al}$ phase 


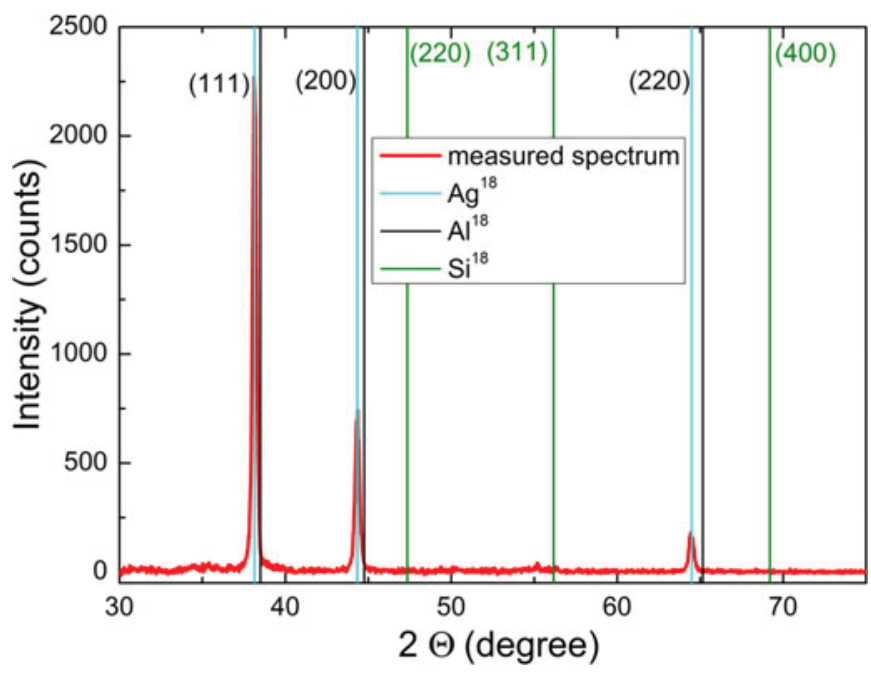

Fig. 2. XRD spectrum of $\mathrm{Ag} / \mathrm{Al}$ spikes grown into an alkaline textured $\mathrm{Si}$ surface. The angular positions of expected $\mathrm{Ag}, \mathrm{Al}$, and reflexes [18] are indicated by vertical lines.

region does not depend on the number of $\mathrm{Al}$ particles in the paste unless two $\mathrm{Al}$ particles are situated close enough to each other that they form one $\mathrm{Ag} / \mathrm{Al}$ region.

EDX measurements of the dark lines and points in Fig. 1(d) show no enhanced $\mathrm{Al}$ or Si content, compared with the rest of the metal spike.

To confirm the crystalline nature of the metal spikes, XRD measurements were conducted. A typical XRD spectrum is shown in Fig. 2. The angles of the reflexes for some Ag, Al, and $\mathrm{Si}$ orientations [18] are plotted, as well as vertical lines. The measurement indicates that the metal exhibits an Ag crystal structure. The $\mathrm{Al}$ and $\mathrm{Si}$, therefore, must be integrated into the Ag lattice. Different Ag peaks appear in the spectrum. This could be explained due to multicrystallinity of the $\mathrm{Ag} / \mathrm{Al}$ spike. Another explanation is that varying orientations of the different spikes on the sample cause the different Ag peaks, as the X-ray spot has a size of around $1 \mathrm{~mm}$, and therefore, several metal spikes are included in the measurement. Since the diffraction pattern in Fig. 1 and the FFTs show the same point pattern for different areas in a single spike, indicating that the metal spikes are monocrystalline, the second explanation is more likely.

In Fig. 3(a), HRTEM image of the Ag/Si interface of a $\mathrm{NaOH}$ etched sample can be seen. The FFTs of the two regions are shown next to the image. No amorphous interfacial layer between the $\mathrm{Ag} / \mathrm{Al}$ spike and the $\mathrm{Si}$ crystal is visible. The same is true for the HRTEM image of the plasma etched samples in Fig. 4. The silicon oxide $\left(\mathrm{SiO}_{\mathrm{x}}\right)$ that can be found in this image stems from the protection layer used during the lamella preparation with FIB. For both surfaces, the $\mathrm{Ag} / \mathrm{Al}$ spikes are of monocrystalline structure as well. In most cases, no interfacial layer could be found between the Si and the Ag crystal. However, a few contact spots, not shown here, were separated from the Si crystal by an amorphous layer (some nanometer thickness). As this layer generally occurs only locally, it should not influence the macroscopic current transport to a large extent.
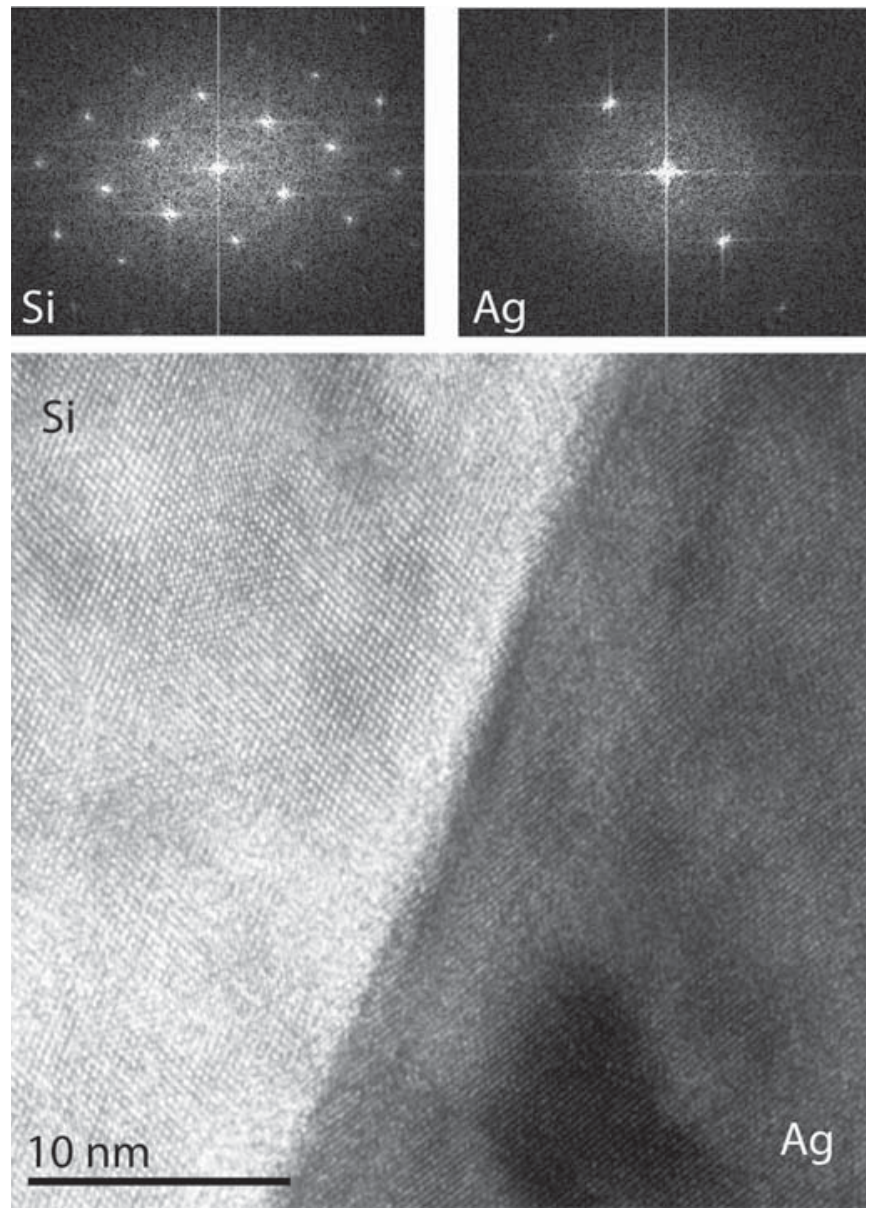

Fig. 3. HRTEM image and FFTs of metal/Si interface on $\mathrm{NaOH}$ etched $\mathrm{Si}$ wafer.

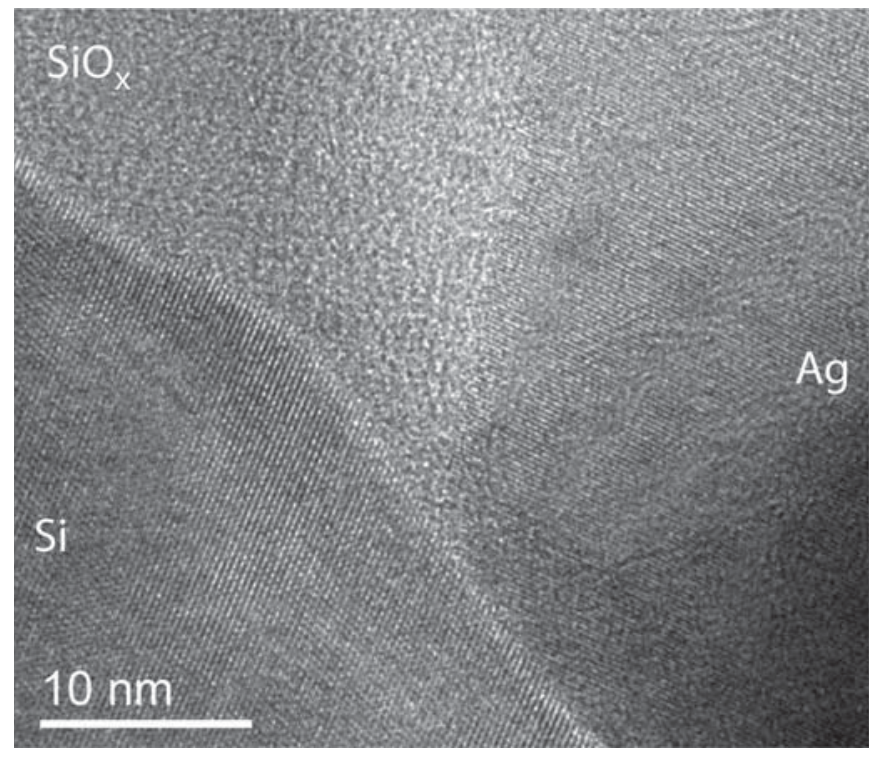

Fig. 4. HRTEM image of metal/Si interface on plasma-textured Si wafer. The $\mathrm{SiO}_{\mathrm{x}}$ stems from protection layer. 

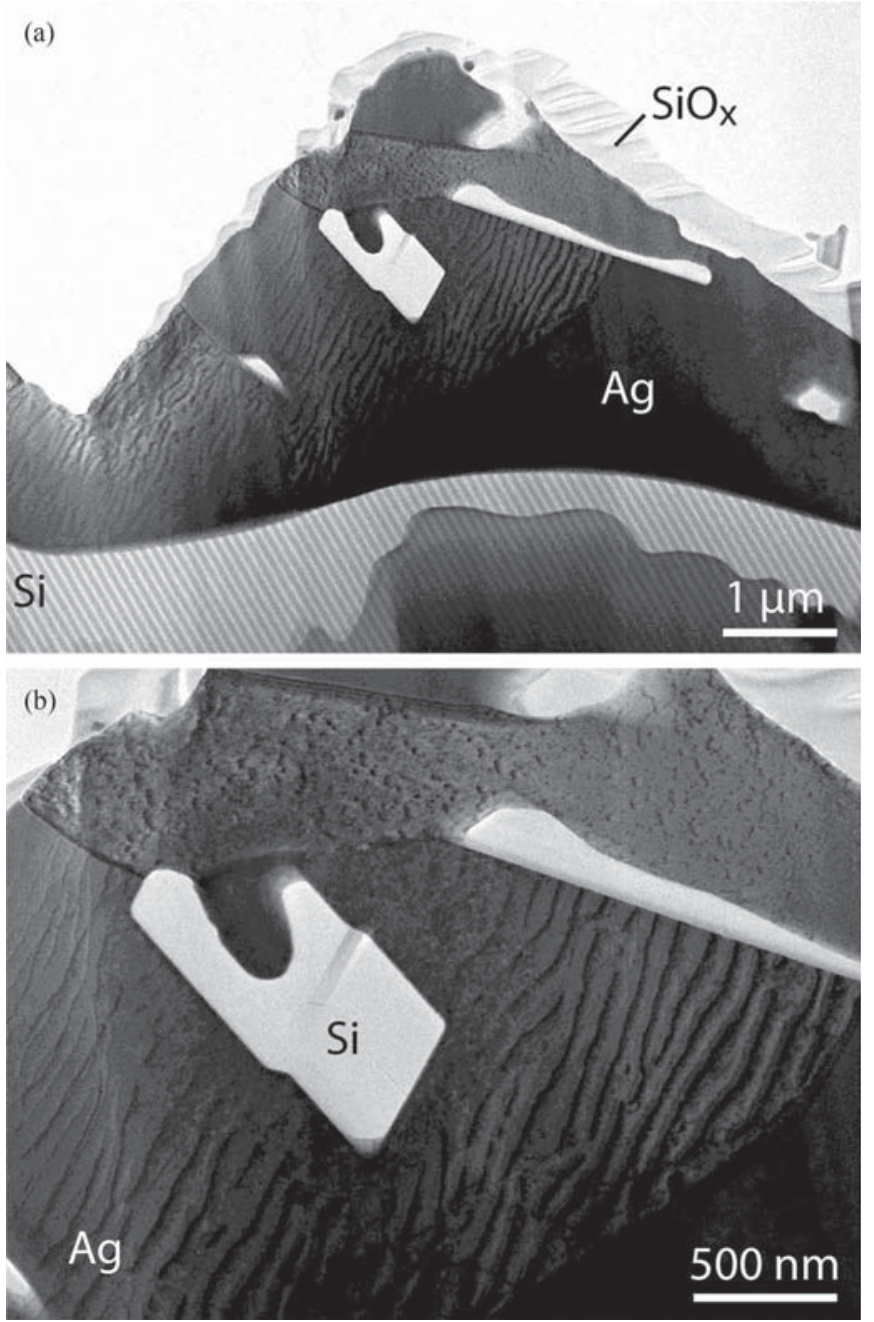

Fig. 5. (a) and (b) STEM images of Ag/Al spike grown on Si wafer (bulk $\mathrm{Si}$ hatched) without $\mathrm{SiN}_{\mathrm{x}}: \mathrm{H}$ layer. The white inclusions in the crystal are multicrystalline $\mathrm{Si}$.

\section{B. Wafer Without SiN $N_{\mathrm{x}}: H$ Layer}

Fig. 5(a) shows a STEM cross section of an $\mathrm{Ag} / \mathrm{Al}$ spike on an alkaline textured sample without $\mathrm{SiN}_{\mathrm{x}}: \mathrm{H}$. The spike does not show the shape of an inverted pyramid. The bright layer on top of the $\mathrm{Ag}$ crystal is a residual $\mathrm{SiO}_{\mathrm{x}}$ protection layer. Inclusions with bright contrast, similar to the ones found in the $\mathrm{Ag} / \mathrm{Al}$ phase of the bulk contact in [11], can be seen in the $\mathrm{Ag} / \mathrm{Al}$ crystal. TEM EDX measurements reveal that these inclusions consist of at least 98 at\% Si as can be seen in the spectrum in Fig. 6(a). For comparison, an EDX spectrum of the metal spike surrounding the inclusion can be seen in Fig. 6(b). On closer inspection [see Fig. 5(b)], some lines are visible in the Si inclusion.

In Fig. 7(a), HRTEM image of a crossover point of some of these lines is shown. The lattice planes visible in the right image (d) in the regions termed I and II show different orientations indicated by the white-dashed lines. Reduced FFTs of the different regions show different crystal orientations.

Fig. 8 shows the interface between the $\mathrm{Si}$ inclusion and the metal spike. A layer of amorphous $\mathrm{Si}$ is clearly visible. This layer has a thickness of around $5 \mathrm{~nm}$ and is surrounding the $\mathrm{Si}$ inclusion.

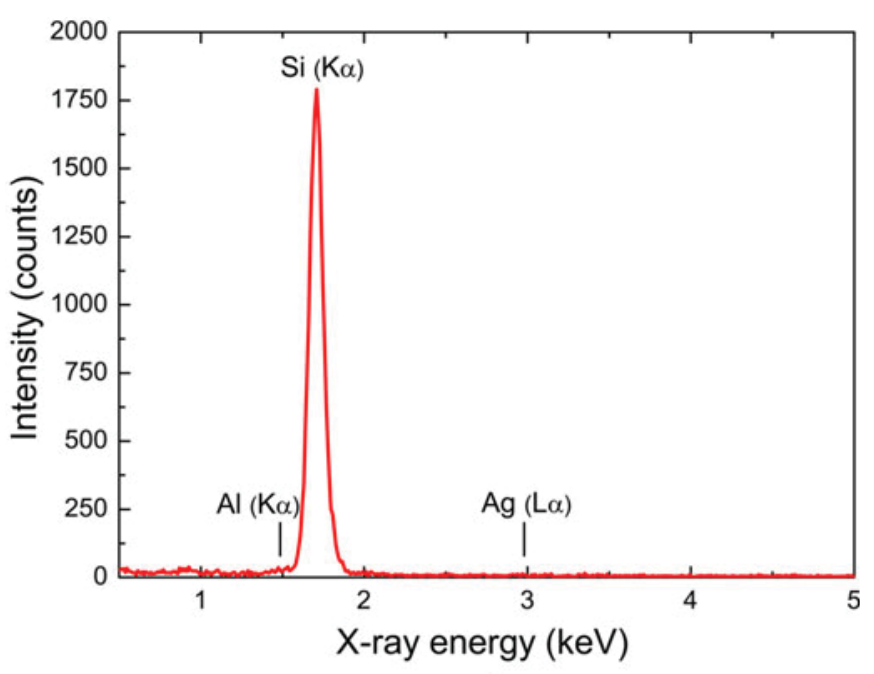

(a)

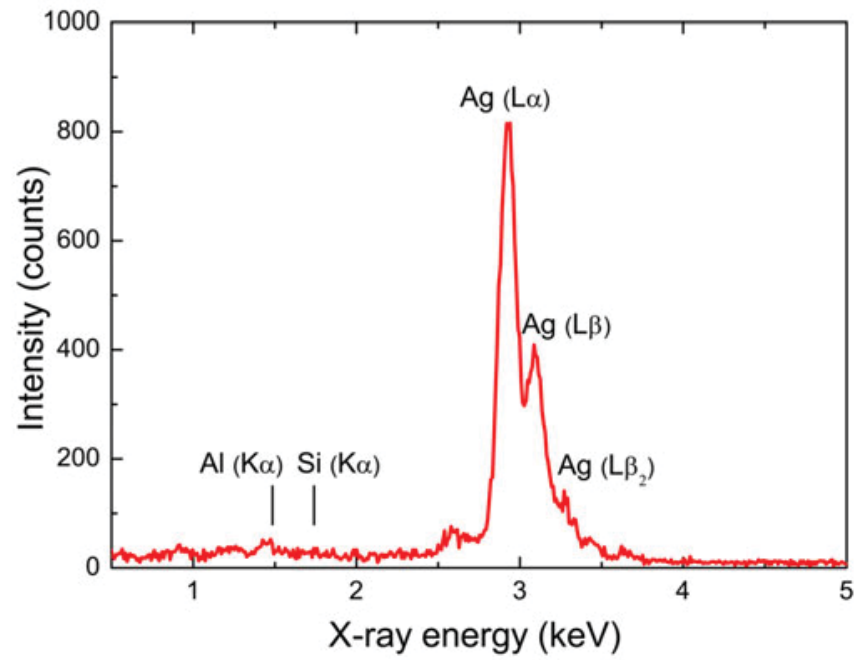

(b)

Fig. 6. EDX spectra of (a) Si inclusion and (b) metal spike in (a).

$\mathrm{Si}$ inclusions like the ones observed here occur as well in contacts on wafers with $\mathrm{SiN}_{\mathrm{x}}: \mathrm{H}$, but less frequently. For overfired samples, however, their number increases on these samples. This temperature dependence can be observed on samples without $\mathrm{SiN}_{\mathrm{x}}: \mathrm{H}$ as well: For lower firing temperatures, fewer inclusions can be found.

\section{Discussion}

The HRTEM images and diffraction patterns of the Ag crystals on the different samples reveal the crystalline nature of the $\mathrm{Ag} / \mathrm{Al}$ spikes. This result is confirmed by XRD measurements of $\mathrm{Ag} / \mathrm{Al}$ spikes of an etched-back contact on an alkaline textured sample. The metal spikes have an Ag crystal structure with Al and Si probably incorporated in the Ag lattice. In contrast with the Ag crystals of pure Ag screen-printing pastes on phosphorous emitters where some crystals show an epitaxial relation to the Si crystal [5], the Ag crystals of Ag/Al do not show the same $\langle 011\rangle$ orientation as the Si substrate, as can be seen by comparing the diffraction patterns of the $\mathrm{Si}$ and the $\mathrm{Ag}$ crystal in the different figures. Additionally, the fact that there are different 

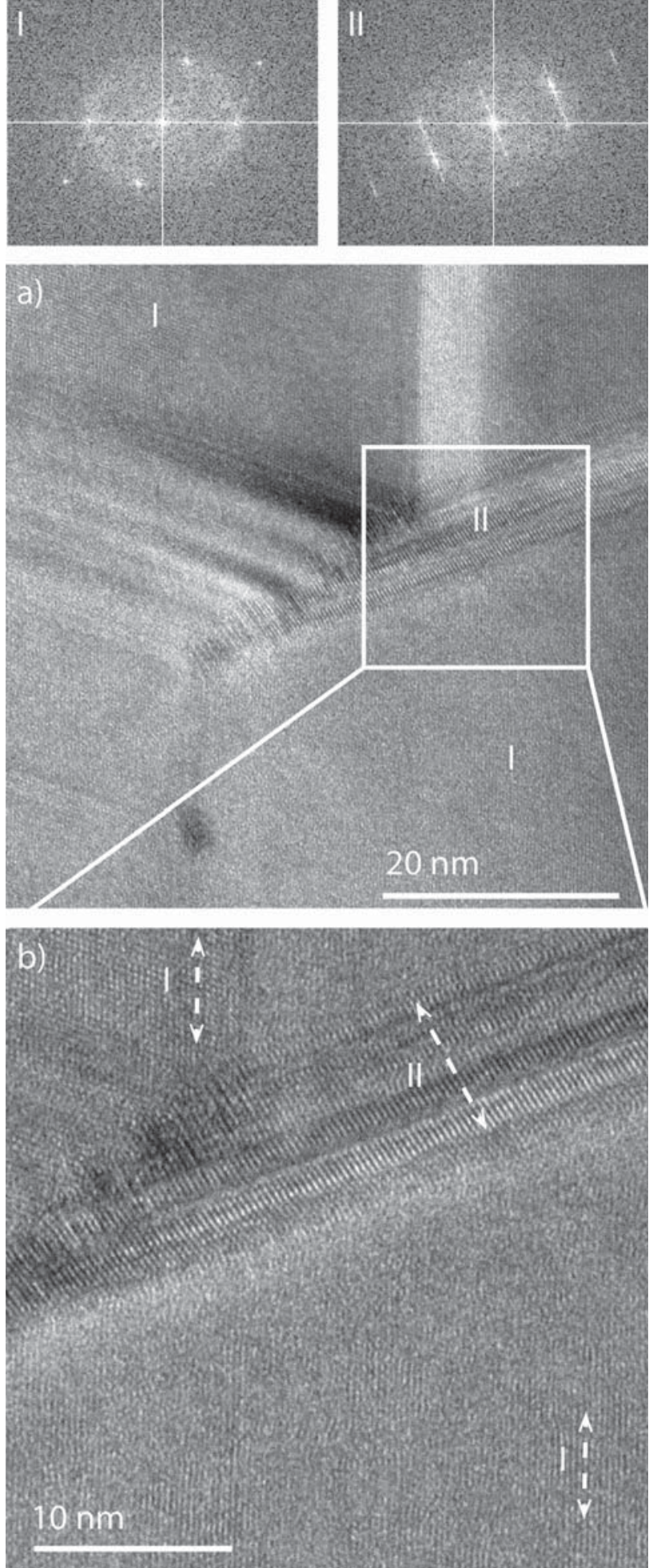

Fig. 7. (a) and (b) SAED of different regions in the Si inclusion. (c) and (d) Magnified HRTEM image of Si inclusion shown in Fig. 6.

Ag peaks in the XRD spectrum confirms that the crystals on one sample feature different orientations. This indicates that there is no particular relation between the $\mathrm{Si}$ and the Ag crystal.

The samples presented in this study show a monocrystalline structure of the metal spikes. Multicrystalline metal areas have

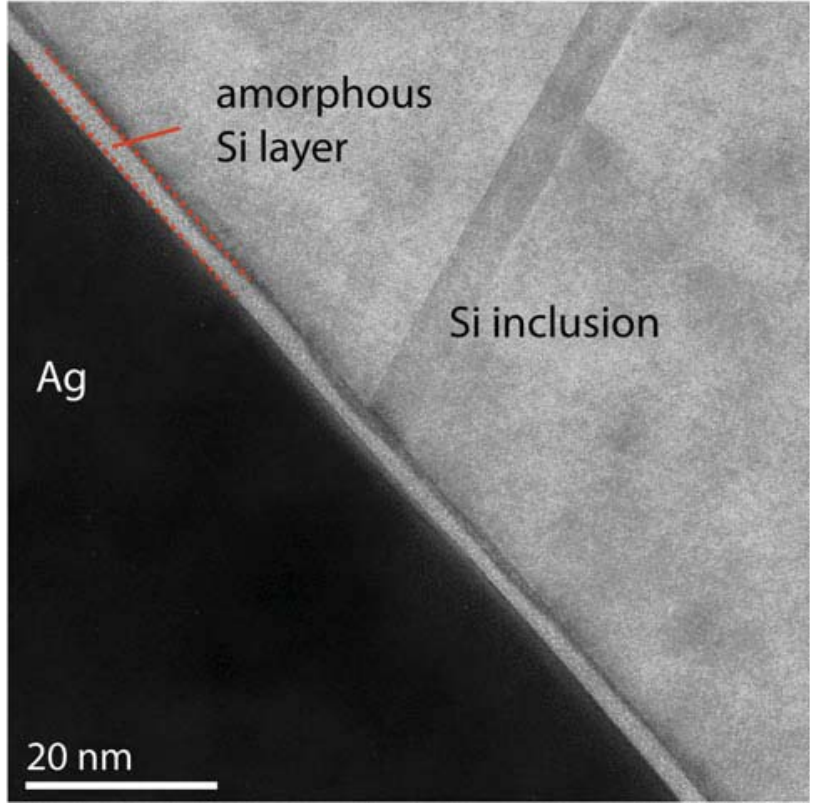

Fig. 8. HRTEM image of an amorphous interface between Ag spike and silicon inclusion.

also been found in another Ag crystal, which is not shown here. It is, therefore, concluded that the Ag spikes normally grow monocrystalline. However, rarely multicrystalline regions form as well. Probably, this occurs at regions in the spike where the crystal growth is disturbed, e.g., at interfaces. As the crystal observed in Fig. 1 seems to be monocrystalline, the lines that can be seen in the STEM image cannot be grain boundaries. They probably present dislocations in the Ag crystals. It is not clear if these dislocations form during crystal growth and cooling down to room temperature or are a result of the lamella preparation using FIB. Another possibility would be that the lines are $\mathrm{Al}$ or Si precipitates that form in the Ag crystal during cool down. As no enhanced $\mathrm{Al}$ or $\mathrm{Si}$ content could be found in these regions, this explanation is improbable but cannot be excluded as the lines are pretty thin.

For the sample without $\mathrm{SiN}_{\mathrm{x}}: \mathrm{H}, \mathrm{Si}$ inclusions can be found in the Ag crystals. These Si inclusions are multicrystalline and surrounded by a thin layer of amorphous Si. They occur more frequently for high firing temperatures. It is assumed that the Si-rich areas in the $\mathrm{Ag} / \mathrm{Al}$ phase in the bulk contact reported in [6] are formed by the same mechanism and are multicrystalline Si precipitates as well. In the firing process, $\mathrm{Si}$ is dissolved in the $\mathrm{Ag} / \mathrm{Al}$ phase. During cooling down of the wafers, Si precipitates in the $\mathrm{Ag} / \mathrm{Al}$ phase of the contact, in the $\mathrm{Ag}$ crystals growing into the $\mathrm{Si}$ surface, and in the $\mathrm{Ag} / \mathrm{Al}$ phase in the bulk contact.

The observations made in this investigation match well with the model for contact formation of $\mathrm{Ag} / \mathrm{Al}$ screen-printing pastes presented in [11], especially the processes taking place during the cooling step. In the firing process at temperatures above $660{ }^{\circ} \mathrm{C}$, the $\mathrm{Al}$ in the screen-printing paste starts to melt and dissolves the surrounding $\mathrm{Ag}$. When the $\mathrm{SiN}_{\mathrm{x}}: \mathrm{H}$ is locally opened below the $\mathrm{Al}$ containing parts of the contact, $\mathrm{Si}$ is dissolved in the $\mathrm{Ag} / \mathrm{Al}$ phase. For samples without $\mathrm{SiN}_{\mathrm{x}}: \mathrm{H}$, this step starts 
earlier as no antireflection layer has to be etched away. Therefore, for samples fired with the same temperature profile, more $\mathrm{Si}$ should be dissolved in the Ag/Al phase for the samples without $\mathrm{SiN}_{\mathrm{x}}: \mathrm{H}$. For higher peak firing temperatures, the Si content in the $\mathrm{Ag} / \mathrm{Al}$ phase rises as well. During cool down, the Si solubility in the $\mathrm{Ag} / \mathrm{Al}$ phase formed during firing is exceeded. $\mathrm{Si}$ precipitates in a multicrystalline form. For higher Si contents in the former $\mathrm{Ag} / \mathrm{Al}$ phase, more Si crystals form. The Ag/Al crystallizes in a (monocrystalline) Ag lattice with incorporated $\mathrm{Al}$ and $\mathrm{Si}$ atoms.

\section{SUMMARY}

In this study, a TEM investigation of metal spikes grown into differently structured $\mathrm{Si}$ surfaces below screen-printed $\mathrm{Ag} / \mathrm{Al}$ contacts has been presented. For the first time, the crystalline nature of the metal spikes was demonstrated. They consist mainly of $\mathrm{Ag}$ with up to $5 \mathrm{at} \% \mathrm{Al}$ and 3 at $\% \mathrm{Si}$ independent of the $\mathrm{Al}$ content of the paste. XRD measurements confirm the crystallinity of the metal. As only Ag reflexes could be found in the $\mathrm{XRD}$ spectrum and no reflexes from $\mathrm{Al}$ and $\mathrm{Si}$, it was concluded that the crystals have an $\mathrm{Ag}$ crystal structure with $\mathrm{Al}$ and $\mathrm{Si}$ incorporated in the Ag lattice.

For all investigated Si surfaces, the crystalline nature of the metal spikes was clearly shown. No particular relation between the Ag crystal and the Si lattice could be found. The presented metals spikes have a monocrystalline structure.

Inclusions found in the Ag crystals of the sample without $\mathrm{SiN}_{\mathrm{X}}: \mathrm{H}$ layer turned out to be multicrystalline Si precipitates. They develop during cool down in the firing step, when the $\mathrm{Si}$ solubility limit is exceeded.

The presented results confirm the model for contact formation of $\mathrm{Ag} / \mathrm{Al}$ screen-printing pastes published recently [11].

\section{ACKNOWLEDGMENT}

The authors would like to thank M. König and M. Hörteis from Heraeus Deutschland GmbH \& Co. KG for the XRD measurements and the supply of screen-printing pastes. J. Bauer from MPI Halle and A. Hähnel from Fraunhofer-IWM Halle are acknowledged for discussion of the results.

\section{REFERENCES}

[1] G. Schubert, "Thick film metallization of crystalline silicon solar cells: Mechanisms, models and applications," Ph.D. dissertation, Dept. Phys., Univ. Konstanz, Konstanz, Germany, 2006.

[2] K. K. Hong et al., "Mechanism for the formation of Ag crystallites in the Ag thick-film contacts of crystalline Si solar cells," Sol. Energy Mater. Sol. Cells, vol. 93, p. 898, 2009.

[3] R. Hönig, "Evaluation and microstructure analysis of thick film contacts for industrial silicon solar cells," Ph.D. dissertation, Albrecht-Ludwigs Univ., Freiburg, Germany, 2014.

[4] C. Ballif, D. M. Huljić, G. Willeke, and A. Hessler-Wyser, "Silver thickfilm contacts on highly doped n-type silicon emitters: structural and electronic properties of the interface," Appl. Phys. Lett., vol. 82, no. 12, pp. 1878-1881, 2003.

[5] G. Schubert, F. Huster, and P. Fath, "Current transport mechanisms in printed Ag-thick film contacts to an n-type emitter of a crystalline silicon solar cell," in Proc. 19th Eur. Photovoltaic Sol. Energy Conf., 2004, pp. 813-816.
[6] M. M. Hilali et al., "Effect of glass frit chemistry on the physical and electrical properties of thick-film Ag contacts for silicon solar cells," J. Electron. Mater, vol. 35, pp. 2041-2047, 2006.

[7] R. Kopecek et al., "Large area n-type multicrystalline silicon solar cells with B-emitter: Efficiencies exceeding 14\%," in Proc. 15th Int. Photovoltaic Sci. Eng. Conf., 2005, pp. 892-894.

[8] R. Lago et al., "Screen printing metallization of boron emitters," Prog. Photovoltaic Res. Appl., vol. 18, pp. 20-27, 2010.

[9] H. Kerp et al., "Development of screen printable contacts for $\mathrm{p}^{+}$emitters in bifacial solar cells," in Proc. 21 st Eur. Photovoltaic Sol. Energy Conf., 2006, pp. 892-894.

[10] J. Engelhardt, A. Frey, S. Gloger, G. Hahn, and B. Terheiden, "Passivating boron silicate glasses for co-diffused high-efficiency n-type silicon solar cell application," Appl. Phys. Lett., vol. 107, art. no. 042102, 2015.

[11] S. Fritz et al., "Formation of Ag/Al screen-printing contacts on B emitters," IEEE J. Photovoltaics, vol. 5, no. 1, pp. 145-151, Jan. 2015.

[12] F. D. Heinz et al., "Microscopic origin of the aluminium assisted spiking effects in n-type silicon solar cells," Sol. Energy Mater. Sol. Cells, vol. 131, pp. 105-109, 2014.

[13] A. Edler et al., "Metallization-induced recombination losses of bifacial silicon solar cells," Prog. Photovoltaic Res. Appl., vol. 23, pp. 20-627, 2015.

[14] F. Kiefer et al., "Emitter recombination current densities of boron emitters with silver/aluminum pastes," in Proc. 40th IEEE Photovoltaic Spec. Conf., 2014, pp. 2808-2812.

[15] S. Riegel, F. Mutter, T. Lauermann, B. Terheiden, and G. Hahn, "Review on screen printed metallization on p-type silicon," Energy Procedia, vol. 21, pp. 14-23, 2012.

[16] S. Fritz et al., "Preservation of Si surface structure by Ag/Al contact spots-An explanatory model," Energy Procedia, vol. 67, pp. 43-48, 2015.

[17] P. W. Hawkes and J. C. H. Spence, Science in Microscopy, vol. 1. New York, NY, USA: Springer, 2007.

[18] R. W. G. Wyckoff, Crystal Structures, vol. 1, 2nd ed. New York, NY, USA: Wiley-Interscience, 1963.

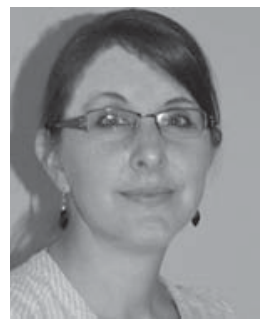

Susanne Fritz was born in Waldshut, Germany. She studied physics with the University of Ulm, Ulm, Germany, and the University of Konstanz, Konstanz, Germany. In 2012, she received the Diploma degree in physics from the University of Konstanz, where her focus was on hydrogen passivation of grain boundaries. She is currently working toward the Ph.D. degree within the Characterization" Group of the Photovoltaics Division, University of Konstanz.

Her major research interests include screenprinted metallization of crystalline Si solar cells, focusing on the contact formation to $\mathrm{p}^{+} \mathrm{Si}$.

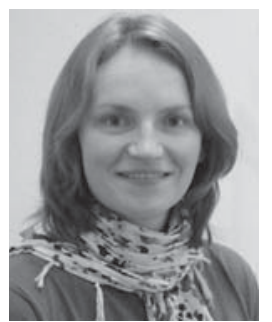

Stefanie Riegel received the Staatsexamen degree in physics and mathematics from the RuprechtKarls-University of Heidelberg, Heidelberg, Germany, in 2006. She is currently working toward the Ph.D. degree with the Industrial Solar Cells Group, Photovoltaics Division, University of Konstanz, Konstanz, Germany.

Her research interests include screen-printed metallization and contact formation of crystalline silicon solar cells. 


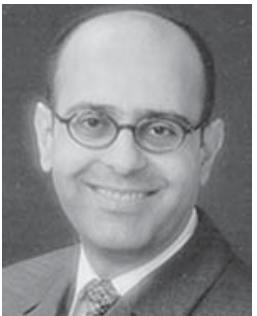

Adnan Hammud received the Diploma degree in electrical power engineering and photovoltaics from Friedrich-Alexander-University, ErlangenNuremberg, Germany, in 2001.

From 2002 to 2006, he was a Research Assistant with the Bavarian Center for Applied Energy Research (ZAE Bayern), Erlangen, and with the Institute for Solar Energy Research Hamelin, Emmerthal, Germany. Up until 2012, he was a self-employed Electrical Engineer in the field of photovoltaics with emphasis on indoor applications.

From 2012 to 2014, he was a Research Associate with the Photovoltaics Division, Department of Physics, University of Konstanz, Konstanz, Germany. His research interests include electron microscopy and applications, as well as the development of innovative and customized solar cells for portable electronic devices.

Mr. Hammud is a Member of both the Association of German Engineers (VDI) and the European Microscopy Society (EMS).

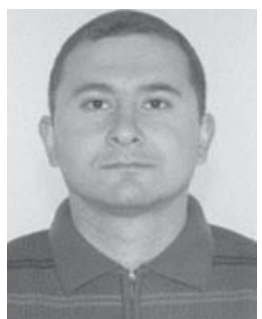

Hakan Deniz was born in Turkey in 1978. He received the B.S. degree in physics from the Boğaziçi University, Istanbul, Turkey, in 2000 and the M.S and $\mathrm{Ph} . \mathrm{D}$. degrees in physics from the University of North Carolina at Chapel Hill, NC, USA, in 2004 and 2007, respectively.

From 2008 to 2011, he was a Postdoctoral Research Fellow with the Institute of Materials Science and Nanotechnology (UNAM), Bilkent University, Ankara, Turkey, working on electron microscopy characterization of nanoscale materials. Since 2011, he has been a Postdoctoral Research Associate with the Max Planck Institute of Microstructure Physics, Halle, Germany, focusing mainly on scanning/transmission electron microscopy of functional oxide materials and solar cells.

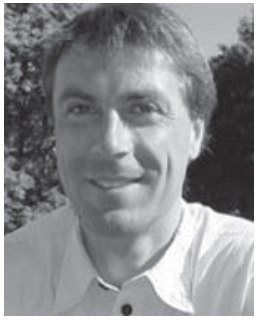

Giso Hahn (M'10) was born in Frankfurt am Main, Germany, in 1969. He received the Diploma degree in physics from the University of Stuttgart, Stuttgart, Germany, in 1995 and the Ph.D. degree in physics from the University of Konstanz, Konstanz, Germany, in 1999. He received the Venia Legendi (Habilitation) degree in experimental physics from the University of Konstanz in 2005.

Since 2009, he has been an Apl. Professor with the Department of Physics, University of Konstanz. $\mathrm{He}$ is also the Head of the Photovoltaics Division, Department of Physics, University of Konstanz, with around 50 employees. His research interests include crystalline silicon materials and solar cell process development, characterization of promising low-cost materials for photovoltaic applications, and development of adapted solar cell processes for these and other materials. He is the author/coauthor of more than 300 publications in journals, books, and conference proceedings and holds several patents.

Prof. Hahn is a Member of the scientific committees of various conference series (e.g., IEEE Photovoltaic Specialists Conference, European Photovoltaic Solar Energy Conference and Exhibition, and International Conference on Silicon Photovoltaics) and workshops. His other scientific and technological achievements include reaching record efficiencies for selected crystalline silicon materials and detailed characterization of efficiency-limiting crystal defects. His group is interested in transferring technologies from the laboratory stage to industry. 